\title{
A soberania alimentar
}

\author{
JACQUES CHONCHOL
}

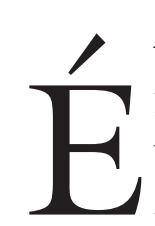

\section{A problemática alimentar no século $\mathrm{XX}$} dentes impossíveis de se pôr no mercado. Por outro lado, os progressos nos conhecimentos científicos sobre a biologia humana conduzem a conceber e analisar o problema da desnutrição. Finalmente, um melhor conhecimento da situação alimentar nos países em desenvolvimento permite uma tomada de consciência do fenômeno da subalimentação e da fome.

No início dos anos de 1930, os especialistas em nutrição humana alertavam sobre a necessidade de aumentar as disponibilidades alimentares simultaneamente ao fato de que os economistas recomendavam reduzir a produção agrícola para resolver o problema dos excedentes invendáveis. Ao mesmo tempo, observa-se que a fome existe para numerosas populações e que há excedentes agrícolas impossíveis de serem postas no mercado. Esse paradoxo é denunciado por Stanley Bruce, ex-primeiro-ministro da Austrália, diante da Sociedade das Nações, o que conduz à instalação de uma comissão para estudar as relações entre a agricultura, a nutrição, a saúde e a economia. Mas a Segunda Guerra Mundial pôs fim prematuramente aos trabalhos dessa comissão.

Essa reflexão, no entanto, continuou durante a guerra, e com seu fim, em 1945, o presidente Roosevelt convocou uma reunião das Nações Unidas sobre a agricultura e a alimentação, da qual participam os representantes de 44 governos. Dessa reunião, surgiria a FAO.

Em 1952, pela primeira vez desde 1939, as disponibilidades alimentares mundiais recuperam o nível do pré-guerra e a etapa de reconstrução está superada. No ano seguinte, reaparecem excedentes nos EUA e a sombra do ocorrido em 1930 assusta os economistas. Ao mesmo tempo, observam-se situações de fome nos países do Extremo Oriente.

Em 1954, a FAO propõe eliminar os excedentes, destinando-os, mediante a Organização de Doações Alimentares, aos países que têm déficit de alimentos. Da mesma forma, os EUA, nesse mesmo ano, aprovam uma lei que estabelece as condições de ajuda alimentar com seus excedentes (P.L. 480). Posteriormente, essa ajuda é substituída por contratos comerciais.

Em 1960, observam-se situações de fome no Extremo Oriente, e a FAO estabelece, em 1962, seu Programa Alimentar Mundial. A comunidade científica internacional apóia os esforços de produção de sementes de trigo e de arroz de 
alto rendimento, e, por volta de 1965, começa na Ásia o desenvolvimento da Revolução Verde, que se estende mais tarde à América Latina. Embora os resultados dessa revolução fossem espetaculares em termos produtivos, suas conseqüências sociais foram muito menos favoráveis. Antes da Revolução Verde, na Índia, $18 \%$ do campesinato não possuía terras. Em 1970, essa porcentagem havia aumentado para $33 \%$.

Apesar desse déficit social, observa-se que os países asiáticos, nos decênios seguintes, aproximam-se da auto-suficiência alimentar, ao mesmo tempo em que a Europa continua aumentando seus rendimentos agrícolas, o que havia se iniciado em 1950 com a modernização da agricultura depois da guerra.

Em 1972, a queda geral da produção cerealista mundial e as compras maciças da URSS esgotam os estoques disponíveis e produzem um aumento considerável dos preços. No mesmo ano, Bangladesh e a Etiópia são atingidas pela fome e, entre 1973 e 1975, a seca produz uma grave crise alimentar no Sahel africano. A FAO convoca então uma grande Conferência Mundial sobre a Alimentação, em 1974, na qual os países participantes se comprometem a fazer desaparecer a fome da superfície da terra no curso dos dez anos seguintes.

Os anos de 1970 constituem o decênio durante o qual a diferença entre os países e as regiões em desenvolvimento, já evidente nos anos de 1960, se acentua. As disponibilidades alimentares por habitante permanecem estagnadas e em níveis muito baixos na Ásia do Sul, ao mesmo tempo em que baixam na África Subsaariana. Ao contrário, as disponibilidades médias melhoram no Oriente Próximo, na África do Norte, na América Latina e no Leste da Ásia.

Mas o que distingue os anos de 1970 dos decênios que os precederam e que os seguiram é o fato de que uma parte do melhoramento da disponibilidade alimentar por habitante dos países em desenvolvimento foi assegurada pelo rápido aumento das importações alimentares provenientes dos países desenvolvidos. As importações líquidas de cereais mais do que triplicaram entre 1969-1971 e 1979-1981.

No início dos anos de 1980, as grandes situações de fome diminuem e as inquietudes a esse respeito são menores. As crises alimentares como a do Sahel se resolvem mediante a Organização de Ajuda Alimentar de Urgência. Por outro lado, os rendimentos dos cultivos continuam aumentando nas regiões do mundo em que as condições são mais favoráveis. Produzem-se excedentes na Europa Ocidental. A produção mundial de trigo triplica desde 1950. A Índia deixa de importar trigo a partir de 1985 e se reduzem os déficits na URSS, China, América Latina e Ásia.

Começam a instalar-se duas novas problemáticas. A primeira delas é a do desenvolvimento. A temática do desenvolvimento agrícola e rural se instala tanto ao nível dos organismos internacionais como das ONGs. A fome não é tanto a conseqüência de uma produção alimentar insuficiente, como da marginalização econômica de certas populações. Conseqüentemente, a prioridade não é tanto 
aumentar a produção dos que já produzem muito, mas dar a todos os meios necessários para produzir. A segunda problemática concerne à pesquisa que deve centrar-se mais exatamente nas regiões semi-áridas, menos favoráveis à produção agrícola. A luta contra a desertificação se impõe como uma necessidade essencial.

Nos anos de 1980, novos fatos influenciam a situação alimentar das populações. Por um lado, a aplicação dos programas de ajuste estrutural impostos pelo FMI provoca numerosas rebeliões em diversos países devido ao aumento da pobreza e da exclusão, sobretudo em meios urbanos. Por outro lado, o desenvolvimento das "revoluções democráticas" na América Latina, nos antigos países do bloco comunista e na África retoma o debate sobre as relações entre a democracia e o desenvolvimento. Em 1989 e 1990, a OCDE considera que as políticas de cooperação internacional devem contribuir para a consolidação das novas democracias.

Por sua vez, o problema dos conflitos políticos agrava, em numerosos países, a situação alimentar das populações. Até o início dos anos de 1980, considerava-se que os grandes déficits alimentares eram influenciados sobretudo por razões climáticas excepcionalmente negativas, e secundariamente por conflitos políticos. Nos anos de 1990, os conflitos políticos convertem-se na causa primeira da necessidade de ajuda alimentar de urgência. Por outro lado, comprova-se que os conflitos que se eternizam podem agravar as condições de produção e abastecimento de numerosas populações. É o caso, por exemplo, no Afeganistão, na Etiópia, no Haiti e no Sudão. Hoje, esses conflitos se converteram em uma das causas essenciais da fome que atinge numerosas populações, como vemos no caso de Serra Leoa, Libéria, Ruanda, Burundi, Somália, Nigéria, Coréia do Norte, Birmânia, além daqueles anteriormente citados.

Finalmente, outro fato que contribuiu para renovar o debate sobre a situação alimentar foi o das condições ecológicas do meio ambiente: desde o aparecimento de ameaças globais resultantes do reaquecimento do planeta e do alerta sobre o desflorestamento dos bosques tropicais até o debate sobre a biodiversidade, em todos os quais os países em desenvolvimento se encontram em primeiro plano na cena ecológica.

Do ponto de vista da disponibilidade alimentar, pode-se dizer que o melhoramento dessas disponibilidades nos países em desenvolvimento tomados em seu conjunto prosseguiu rapidamente até meados dos anos de 1980 e de forma mais lenta posteriormente. Mas a África ao Sul do Saara continuou retrocedendo, a América Latina e o Caribe não fizeram, praticamente, novos progressos, e o Oriente Próximo e a África do Norte progrediram apenas modestamente. Por outro lado, os avanços prosseguiram no Leste da Ásia e, sobretudo, no final dos anos de 1980, na Ásia do Sul.

Ao lado de numerosos países em desenvolvimento que não conseguiram muitos progressos para aumentar suas disponibilidades de alimentos e que ainda retrocederam em cifras líquidas, encontram-se os que fizeram progressos con- 
sideráveis. Mas o que distingue os países desenvolvidos daqueles em desenvolvimento é que estes últimos não têm a capacidade que seria necessária para conservar os progressos obtidos em matéria de disponibilidade alimentar por habitante quando têm de enfrentar situações de guerra ou quando ocorrem catástrofes econômicas mais profundas. Como a proporção da renda total consagrada à alimentação nos referidos países é importante, as eventuais reduções da renda traduzem-se na diminuição da demanda de produtos alimentícios. Além disso, as penúrias alimentares e as altas de preços se traduzem em baixas significativas da renda, o que constitui um círculo vicioso.

Por sua vez, a tendência dos países em desenvolvimento a converterem-se em grandes importadores de cereais, particularmente desde os anos de 1970, teve como contrapartida a orientação crescente para a exportação da produção cerealista dos grandes países desenvolvidos como a América do Norte e a Oceania. Paralelamente, a Europa Ocidental aplica políticas de sustentação de preços que lhe permitiram converter-se também em uma legítima região exportadora de cereais desde os anos de 1980.

\section{Perspectivas no horizonte: 2010}

Para analisar as políticas que permitiriam garantir a segurança alimentar, é necessário considerar previamente quais são as perspectivas para os próximos anos. Isto será feito a partir de hipóteses para o horizonte 2010, estabelecidas pela FAO para a demanda, a oferta, o comércio e a nutrição.

No horizonte considerado do ano 2010 , a população mundial poderá alcançar a cifra de sete bilhões de habitantes. Do aumento de um bilhão com relação ao ano 2000, 94\% encontrar-se-ia nos países em desenvolvimento. As taxas de crescimento demográfico para as diferentes regiões são muito diversas, desde, no máximo, 2,9\% a cada ano para a África ao Sul do Saara, até 1,2\% para a Ásia do Leste.

As tendências demográficas dos países em desenvolvimento, nos quais os níveis de consumo por habitante são ainda reduzidos, exigiriam um crescimento considerável e contínuo das disponibilidades alimentares.

As avaliações detalhadas concernentes à produção indicam que o crescimento da produção agrícola mundial vai diminuir daqui até o ano 2010 e poderia ser de $1,8 \%$ ao ano $(0,25 \%$ ao ano se considerarmos a produção por habitante). Trata-se, em grande parte, da continuação das atuais tendências a longo prazo. A produção mundial progrediu no ritmo de 3\% ao ano durante os anos de $1960,2,3 \%$ ao ano durante os anos de 1970 e $2 \%$ ao ano no transcurso do período 1980-1992.

$\mathrm{O}$ aspecto negativo desse menor crescimento está ligado ao fato que ocorre e continuará ocorrendo, ao mesmo tempo em que numerosos países e uma grande parte da população mundial têm ainda níveis de consumo e condições de acesso aos alimentos totalmente insuficientes, o que explica a persistência de uma considerável subalimentação. Em resumo, o lento aumento do crescimento agrí- 
cola mundial explica-se também pelo fato de que as pessoas que poderiam consumir mais não dispõem de renda suficiente para demandar um suplemento de produtos alimentares e suscitar assim uma maior produção. A produção mundial poderia progredir mais rapidamente se a demanda solvente aumentasse com maior velocidade.

As perspectivas demográfica e de desenvolvimento global revelam, assim como as avaliações dos estudos da FAO concernentes à produção, o consumo e os intercâmbios, que as disponibilidades alimentares por habitante destinadas ao consumo humano direto continuarão aumentando no conjunto dos países em desenvolvimento e passarão, de 2.500 calorias nos anos 1990-1992, a pouco mais de 2.700 no ano 2010. É provável que, nessa ocasião, as regiões do Oriente Próximo, da África do Norte, da Ásia do Leste e da América Latina alcancem ou ultrapassem o limiar das três mil calorias, o que constituiria uma melhoria considerável, especialmente para a Ásia do Leste. A Ásia do Sul, por sua vez, poderia igualmente registrar progressos importantes, mas em 2010 a situação não será ainda muito favorável. Por outro lado, na África ao Sul do Saara, as disponibilidades alimentares por habitante permaneceriam extremamente reduzidas.

Nessas condições, a incidência da subalimentação crônica poderia diminuir nas três regiões nas quais as perspectivas são melhores. A situação também poderia melhorar na Ásia do Sul, mas corre-se o risco de ter ainda 240 milhões de pessoas subalimentadas nessa região em 2010. A subalimentação crônica continuaria subsistindo na África ao Sul do Saara, onde afetaria $35 \%$ da população, ou seja, cerca de trezentos milhões de pessoas. Em números absolutos, a desnutrição tenderia a deslocar-se da Ásia do Sul para a África ao Sul do Saara. Em nível global, as estimativas da FAO consideram que poderia afetar 730 milhões de pessoas nos horizontes do ano 2010, contra oitocentos milhões atualmente.

Os principais países desenvolvidos exportadores de cereais têm perspectivas de crescimento de suas exportações para os países em desenvolvimento que lhes oferecem ainda possibilidades de expansão da produção e das exportações, mas a progressão de suas exportações líquidas para o resto do mundo se anuncia muito mais modesta. Isso se explica pelo fato de que o grupo dos antigos países socialistas europeus deixará de ser um grande importador e poderia ainda converter-se em legítimo exportador de quantidades modestas de cereais.

Nas exportações líquidas totais, as partes de mercado das três principais regiões exportadoras da OCDE, a saber, Europa Ocidental, América do Norte e Oceania, poderiam modificar-se sensivelmente. A reforma das políticas atuais conduzirá provavelmente a Europa Ocidental a não aumentar suas exportações líquidas além dos níveis alcançados no final dos anos de 1980. Se isso ocorrer, a totalidade das exportações suplementares dos três grupos proviria da América do Norte e da Oceania.

O crescimento da produção animal deveria permanecer bastante importante nos países em desenvolvimento. Uma parte crescente das importações 
cerealistas desses países serviria para aumentar a produção e o consumo de produtos animais. Esse crescimento das disponibilidades cerealistas utilizadas para alimentação animal poderia criar problemas, dada a persistência da subalimentação dos pobres. Um aumento nos preços dos cereais devido a essa demanda para a produção animal faz correr o risco de excluir do mercado um maior número de pobres em seu consumo direto de cereais.

As importações líquidas dos produtos agrícolas dos países em desenvolvimento progredirão provavelmente mais rápido que suas exportações líquidas de produtos de base. Essas tendências anunciam que a balança comercial agrícola nos países em desenvolvimento, que até agora foi superavitária, poderia tornarse deficitária, tendência que se observa há algum tempo.

Quando são examinados os recursos para a produção agrícola, a superfície das terras atualmente utilizadas para a produção vegetal nos países em desenvolvimento (sem incluir a China) chega a 760 milhões de hectares, dos quais 120 milhões são irrigados; entre estes últimos, 36 milhões estão situados em zonas áridas. Esses 760 milhões de hectares representam somente $30 \%$ da superfície total de terras aptas suscetíveis em grau diverso de serem utilizadas para a produção agrícola.

Mas essa visão mais exatamente otimista deve ser moderada pelos seguintes fatos:

a) Cerca de $92 \%$ das novas terras aptas para a produção agrícola que ainda não foram exploradas estão situadas na África ao Sul do Saara e na América Latina. Não existem mais novas terras possíveis de serem cultivadas na Ásia do Sul, no Oriente Próximo, nem na África do Norte.

b) Os dois terços dessas novas terras possíveis de serem incorporados encontram-se somente em um pequeno número de países: Brasil, Zaire, Indonésia, Sudão, Argélia, Moçambique, Tanzânia, Argentina, Bolívia, Colômbia, México, Peru, Venezuela.

c) Uma grande parte dessa reserva teórica de terras está coberta por bosques e não está real e facilmente disponível para a expansão da agricultura.

d) Uma proporção muito importante dessas terras se caracteriza por ter solos ou uma topografia pouco favoráveis para a produção agrícola.

e) Finalmente, os estabelecimentos humanos e as infra-estruturas ocupam uma parte das terras aptas para a agricultura, que se estima que alcance aproximadamente 3\% delas, e essa proporção poderia chegar a ser de $4 \%$ no ano 2010.

A superfície de terras irrigadas poderia aumentar nos países em desenvolvimento daqui até o ano 2010 em cerca de 23 milhões de hectares, mas uma boa parte desses novos hectares serviria somente para substituir as perdas de terras atualmente irrigadas, seja pela escassez de água, seja pela salinização. 
Quando são examinadas as possibilidades de aumentar os rendimentos dos principais cultivos (cereais, soja), a taxa de crescimento anual média desses rendimentos seria, sem dúvida, muito inferior à que se conseguiu nos últimos vinte anos. $\mathrm{O}$ crescimento da produção de trigo e de arroz enfraqueceria consideravelmente durante esse período em comparação com os decênios precedentes. Para os cereais secundários, a taxa de crescimento, sem dúvida, será mantida, devido à forte expansão da demanda por cereais forrageiros.

Dado que o aumento da produção dependeria em grande medida da progressão dos rendimentos, pode-se perguntar se, posteriormente à revolução verde, é ainda possível aumentar consideravelmente tais rendimentos. Isso não parece fácil, dados os parâmetros agro-ecológicos das novas terras disponíveis.

As preocupações que suscitam o estado do meio ambiente e a diminuição dos recursos em terra e em água por habitante, assim como sua degradação, obrigam a formular a seguinte pergunta: em que medida as limitações ligadas aos recursos e ao meio ambiente podem condicionar as perspectivas de aumento das disponibilidades alimentares e o acesso de todos aos alimentos, o que é a própria essência da segurança alimentar?

Há que considerar também um certo número de fatores interdependentes que são decisivos no aumento da disponibilidade alimentar por habitante: crescimento econômico que faz retroceder a pobreza, função múltipla do crescimento agrícola na maioria dos países em desenvolvimento (aumento das disponibilidades alimentares, criação de empregos e atividades remuneradas para os pobres de forma direta ou indireta, graças aos laços da agricultura com outros setores da economia), capacidade de importar alimentos, políticas econômicas gerais, não existência de tensões políticas que provoquem situações de fome etc.

\section{As duas teses que se opõem hoje}

Com base nos dados anteriores - evolução da problemática alimentar no século XX, existência de situações de fome fundamentalmente por motivos políticos, perspectivas do horizonte em torno de 2010 -, é possível então considerar mais objetivamente as condições da segurança alimentar das populações nos próximos anos.

Globalmente, duas grandes teses se opõem sobre a situação alimentar em um futuro próximo. Por um lado, estão os que acreditam que o crescimento da produção não será capaz de fazer frente às necessidades alimentares devido ao aumento demográfico previsto, a necessidade de melhorar os atuais níveis de nutrição de cerca de oitocentos milhões de pessoas que estão subalimentadas, a mudança nos hábitos alimentaresnà medida que as populações enriquecem, o que demanda uma maior quantidade de recursos para assegurar a alimentação (consumo crescente de produtos de origem animal, por exemplo), as perdas de recursos em águas e em terras úteis devido à degradação dos solos, a desertificação, a erosão e a salinização, a competição com outros usuários pela utilização das águas (consumo urbano e industrial), a expansão urbana e dos caminhos que 
devoram cada vez mais terras úteis para a agricultura, o impacto possível dos fenômenos ecológicos etc.

Por outro lado, encontram-se os que pensam que os progressos tecnológicos, particularmente das biotecnologias, a valorização e a recuperação de recursos naturais, e o progresso para modos de produção mais duradouros etc., permitirão que o crescimento da produção se adapte ao crescimento das necessidades.

Pessoalmente, inclinamo-nos mais para esta segunda alternativa, sem esquecer que pode ocorrer, em alguns momentos, ruptura do equilíbrio entre produção e necessidades, o que implica a obrigação de manter constantemente um certo nível de reservas que garanta a segurança alimentar de todos.

Mas, apesar disso, a fome de milhões de seres humanos não poderá ser superada enquanto se considerar que o funcionamento dos mercados e dos intercâmbios internacionais por si só pode resolver esse problema. Parece-nos absolutamente essencial, além do bom funcionamento dos mercados, a aplicação de políticas complementares de desenvolvimento que diminuam as incertezas e assegurem a satisfação das necessidades alimentares de todos.

Para conseguir isso, porém, será necessário voltar a dar, à finalidade da segurança alimentar, a prioridade que teve há alguns anos no contexto internacional e que aparece hoje, na visão geral sobre o terceiro mundo, ultrapassada por outros tipos de problemas mais urgentes, como a extensão da aids, os conflitos regionais ou étnicos, a corrupção, a imigração selvagem, as drogas e o fundamentalismo religioso. Enquanto esses últimos fenômenos se apresentam como ameaça para o mundo ocidental, as situações de fome atuais se associam sobretudo a fenômenos de guerras regionais ou étnicas.

Por outra parte, a erosão do papel dos estados no mundo desenvolvido, conseqüência da visão neoliberal dominante, centrada sobretudo nos mercados, diminuiu consideravelmente a importância que as políticas públicas nacionais e as de cooperação internacional tinham anteriormente na solução do problema da segurança alimentar. A abertura dos mercados e o aparecimento em um mundo multipolar de numerosos atores - multinacionais, importadores e exportadores - fizeram a alimentação perder o papel estratégico que tinha anteriormente. Isso também está ligado à menor consideração que se tem hoje com o mundo rural com relação ao urbano, no qual parece concentrar-se a modernidade, e ao maior interesse pelos consumidores urbanos, que são consideravelmente privilegiados com relação aos interesses dos produtores camponeses.

Para garantir a segurança alimentar, seria necessário reter também as experiências contrastadas dos países em desenvolvimento da Ásia e da África desde os anos de 1960. Na Ásia do Sudeste, do Japão à Indonésia, os governos deram, já há algum tempo, prioridade à agricultura: investimentos significativos para melhorar a produtividade da produção arrozeira, seu alimento de base, e sistemas de distribuição e intervenção para assegurar a estabilidade do preço do arroz nos 
mercados internacionais. Os mercados internacionais, por sua vez, serviram para exportar produtos manufaturados que requeriam uma mão-de-obra importante. O contraste com as estratégias de desenvolvimento nos países africanos é notório. Em quase todos os lugares na África, a agricultura e a infra-estrutura rural foram menosprezadas e o setor industrial serviu sobretudo para produzir bens de substituição de importações. Isso fez com que os países africanos perdessem, setor por setor, sua competitividade nos mercados mundiais.

Por que essas divergências? Uma boa parte do fracasso da África e do êxito da Ásia do Sudeste deve-se a estratégias agrícolas diferentes. Os Estados do Sudeste Asiático mantiveram um meio macro-econômico favorável à exportação. Em seguida, esforçaram-se por garantir a segurança alimentar de seus consumidores, tanto da cidade quanto do campo. Se o conseguiram, foi tanto por razões econômicas como políticas. Dadas as diferenças importantes entre a população e os recursos agrícolas, por um lado, e o consumo de arroz com relação ao oferecimento desse produto nos mercados mundiais, por outro, esses países se viram obrigados a desenvolver programas intensivos de intensificação de sua produção arrozeira para alimentar seus habitantes. As políticas que realizaram a estabilização dos preços internos do arroz tiveram um papel essencial em sua segurança alimentar e foram igualmente um elemento determinante do investimento e, conseqüentemente, da decolagem econômica da Ásia do Sudeste.

Quais são as políticas de desenvolvimento que parecem indispensáveis para garantir a segurança alimentar do conjunto da população mundial nos próximos anos, no contexto do que foi apontado?

A primeira é que, em uma economia de mercado, a fome e a subalimentação não podem ser superadas se o conjunto dos consumidores não dispuser de rendimentos suficientes para garantir a satisfação de suas necessidades alimentares, assim como de outras necessidades essenciais para sua vida. Isso nos conduz ao problema da segurança do emprego, na medida em que este garante a renda e o nível de rendimentos suficiente para assegurar a satisfação do conjunto das necessidades essenciais.

No caso do rendimento agrícola, isso implica um sistema de produção que não concentre a produção e a renda entre a minoria de grandes agricultores que dispõe de mais terras, de financiamento para a produção e que pode atingir o mercado em condições favoráveis. É por isso que todo sistema de intensificação da produção, no qual a maior parte desta é obtida por um pequeno número de grandes produtores modernizados, e os pequenos produtores familiares ou subfamiliares ficam marginalizados assim como os trabalhadores sem terra, não pode garantir e, pelo contrário, agrava a segurança alimentar nos campos. Isso é, em grande parte, o que tende a ocorrer hoje em muitos países em desenvolvimento, como vemos no caso da América Latina. As políticas públicas de reforma agrária, de crédito, de investimento e de comercialização devem, pois, ir contra essa tendência à concentração da produção. 


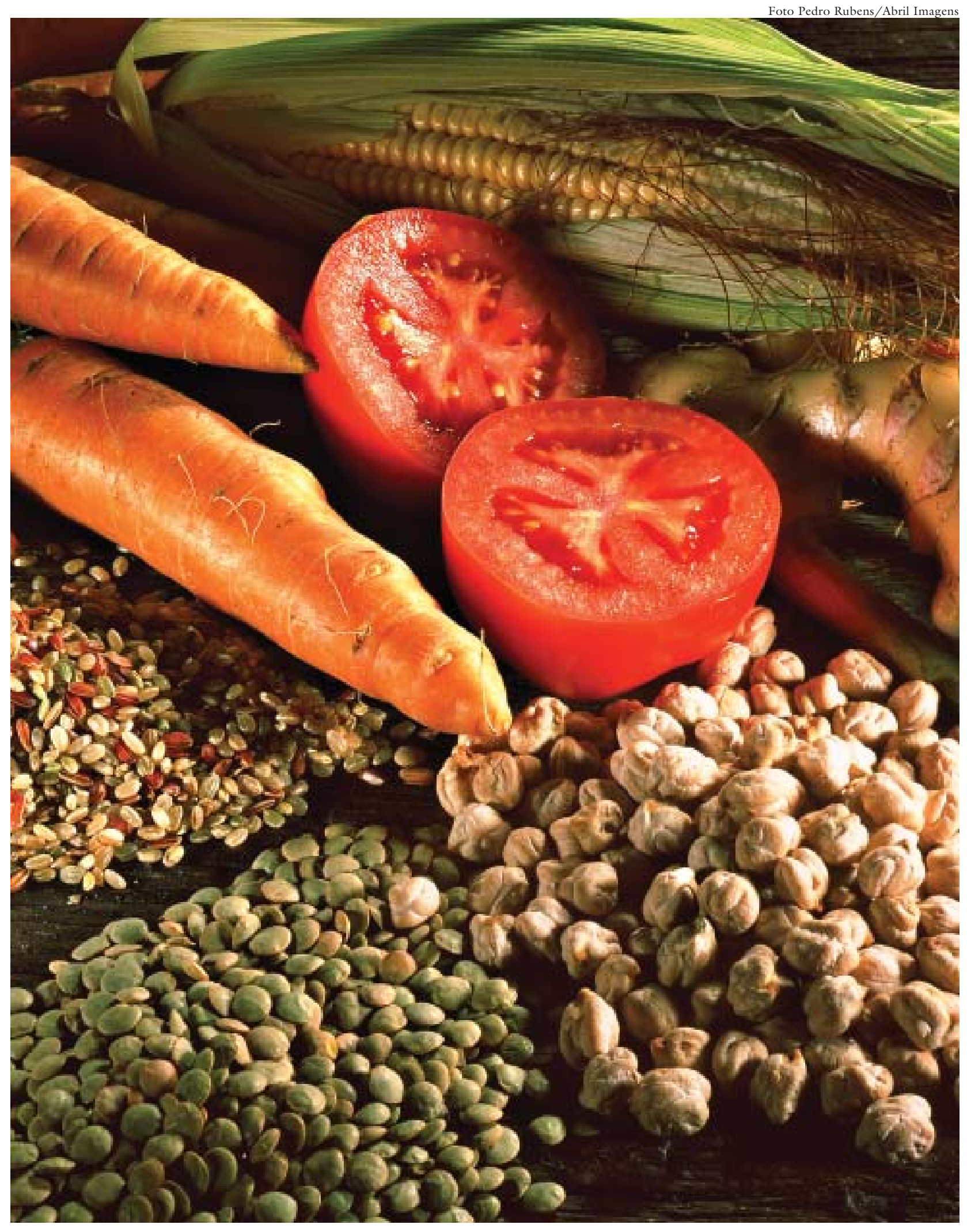

Legumes, verduras e frutas: os problemas da pobreza aumentam a insegurança alimentar urbana. 
No caso do rendimento urbano, o problema da falta de políticas que tenham como objetivo alcançar o pleno emprego, assim como a existência de políticas de produtividade que buscam reduzir o emprego e a renda dos trabalhadores, e a não existência de políticas sociais suficientes para resolver os problemas da pobreza aumentam a insegurança alimentar urbana. O mesmo ocorre com a aplicação de políticas de ajuste estrutural baseadas no crescimento das exportações, das privatizações e na redução do papel do Estado.

A experiência dos países asiáticos mostra que o crescimento das exportações e da industrialização, com toda a importância que possa ter, não basta por si só para melhorar a situação alimentar se não for acompanhado ou presidido por políticas agrícolas voluntaristas que permitam aos agricultores se beneficiarem com o crescimento.

Devido ao fato de que a maioria dos recursos em terras úteis e em capacidade tecnológica para aumentar os lucros se encontra hoje em dia concentrada nos países ocidentais industrializados, alguns pensam que no porvir o problema do aumento das necessidades alimentares dos países em desenvolvimento pode ser resolvido mediante o aumento das importações provenientes dos países desenvolvidos. Essa hipótese é absolutamente irrealista porque não somente seria necessário aumentar a produção nestes últimos em volumes enormes, o que teria conseqüências ecológicas negativas para seus recursos, mas porque, além disso, há o fato de que, como nos encontramos em economia de mercado, isso propõe o problema em divisas dessas exportações e de poder de compra das populações rurais e urbanas envolvidas. No fato, não se pode separar demais o problema da produção do problema do consumo, porque, para que as populações dos países em desenvolvimento possam consumir sua alimentação, é necessário que seu trabalho de produção agrícola, industrial ou em outros setores lhes garanta um nível de rendimento suficiente para isso. Os intercâmbios internacionais não podem ser, em nenhum caso, senão um complemento das produções alimentares internas, sem o qual não pode haver segurança alimentar real das populações. As importações alimentares são também um elemento indispensável no caso de situações de fome que se originam em conflitos políticos ou em catástrofes naturais.

Os países em desenvolvimento experimentaram até hoje um considerável aumento de suas importações alimentares, as quais passaram de cerca de vinte milhões de toneladas no começo dos anos de 1960, ou seja, $2 \%$ de seu consumo de cereais, para 120 milhões de toneladas no começo dos anos de 1990, ou seja, $10 \%$ de seu consumo. Se nada mudar, dado seu intenso crescimento demográfico, a urbanização acelerada, a modificação de suas estruturas sociais e o fraco apoio a suas agriculturas, essas importações poderão alcançar 160 milhões de toneladas no ano 2010. Esse aumento de sua dependência alimentar lhes criaria, sem dúvida, graves problemas financeiros e de balança comercial que não podem evitar senão mediante um esforço acrescido de auto-suficiência para seus alimentos básicos. Esse esforço é também necessário para assegurar a sua população rural 
um rendimento que lhes permita satisfazer suas necessidades alimentares e de outro tipo.

No caso de conflitos políticos ou de catástrofes naturais, quando situações de fome podem ocorrer, é indispensável definir uma estratégia de intervenção sobre a atitude das comunidades afetadas para resolver seus problemas por si mesmas, salvo em situações transitórias que devem ser superadas o mais rapidamente possível.

As estratégias de intervenção devem deter-se nos seguintes princípios:

1) As intervenções devem ser dirigidas diretamente aos grupos vulneráveis.

2) As populações atingidas devem estar envolvidas na identificação e na colocação em operação das respostas consideradas.

3 ) Deve ser dado um apoio aos mecanismos de reação desenvolvidos pelas próprias populações a fim de permitir-lhes limitar sua dependência da ajuda exterior. A ajuda alimentar deve ser prevista por períodos muito curtos e deve ser acompanhada de ações que permitam às populações desenvolver mecanismos de acesso aos produtos alimentícios.

4) Uma sensibilização das populações quanto à educação para a saúde, a educação alimentar e a qualidade da água deve ser posta em operação.

Esse conjunto de considerações nos parece ser o fundamento para abordar corretamente os problemas da luta contra a fome e da segurança alimentar nos próximos anos.

\section{A segurança e a soberania alimentar na América Latina}

Em função das considerações anteriores, devemos acrescentar algumas questões mais específicas sobre a segurança e a soberania alimentar na América Latina.

Vejamos primeiro o que ocorreu nos últimos anos do ponto de vista da produção agrícola. Como conseqüência dos processos de reforma e de ajuste econômicos ocorridos nos anos de 1980 e 1990, e no caso de alguns países como o Chile com anterioridade - desregulação dos mercados, abertura econômica, privatizações e retração do Estado - as condições de produção do setor agrícola modificaram-se de maneira significativa. Dado que a disponibilidade de crédito se reduziu e seu custo subiu, que a concorrência externa derivada da abertura comercial se intensificou, em geral a taxa de câmbio se supervalorizou e houve uma maior necessidade de recursos para financiar funções que antes eram cobertas pelo Estado, a taxa mínima de juros foi elevada para tornar rentável a atividade agropecuária.

Isso, por sua vez, induziu a mudanças na estrutura produtiva a favor dos produtos com maior demanda no âmbito mundial (frutas, hortaliças, flores, sementes, oleaginosas, produtos florestais e carnes de aves) e em detrimento de produtos tradicionais da região como trigo, café, açúcar, algodão e banana, com preços em declínio nos mercados internacionais ${ }^{1}$. 
Os produtos que mostraram as maiores taxas de crescimento nos anos de 1990 foram sobretudo os realizados pelos produtores mais modernizados, com maior acesso a melhorias técnicas, capital e tecnologias, enquanto os cultivos realizados pelos pequenos agricultores familiares ou minifundiários mostraram estagnação ou retrocesso.

Outro dos traços sobressalentes do atual processo de reestruturação da agricultura latino-americana é a crescente influência dos grandes grupos multinacionais de insumos básicos, como agroquímicos e sementes, os quais, mediante a entrega de pacotes tecnológicos, determinaram de modo cada vez mais direto as formas de subcontratação e a distribuição temporal das tarefas produtivas preparação de solos, semeadura, colheita e outras - com que operam amplos setores de agricultores primários.

As mudanças nas condições produtivas manifestam-se também em um aumento da mecanização e do uso de insumos químicos como fertilizantes e pesticidas.

A presença desses fatores permitiu a muitos países da região um aumento significativo da produtividade agrícola, especialmente nos produtos mais dinâmicos e nas unidades de produção mais modernizadas, mais capitalizadas e com melhores terras.

No que se refere agora à população rural, esta cresceu lentamente em valores absolutos, passando de cerca de 122 milhões de pessoas em 1980 para 127 milhões no ano 2000. Isso se deve à continuidade da migração campo-cidade, devido às mudanças tecnológicas poupadoras de trabalho e às transformações da estrutura produtiva, com uma diminuição da superfície cultivada e uma importante expansão das atividades que fazem uso pouco intensivo da mão-de-obra, como a pecuária, os cultivos oleaginosos e as plantações florestais.

A população ativa agrícola da região em seu conjunto ficou, em conseqüência, praticamente estagnada em 44 milhões de pessoas no período 1980-2000, com uma leve diminuição no final do período. Os principais aumentos da população ativa agrícola ocorreram na categoria dos trabalhadores autônomos e dos familiares não-remunerados, enquanto as maiores reduções ocorreram entre os assalariados. As diferenças, entre o leve aumento da população rural e a diminuição da população ativa agrícola, explicam-se por um aumento, nas áreas rurais, de empregos ligados a atividades comerciais, de transporte e de serviços vinculadas à agricultura.

Os aumentos das novas produções destinadas ao mercado de exportação e em alguns casos ao mercado interno não conseguiram, dado o tipo de empresas em que se fizeram e seus modos de funcionamento, compensar a perda de empregos derivada da não expansão da fronteira agrícola e do aumento da pecuária e da indústria florestal, posto que estas últimas foram atividades de uso pouco intensivo de mão-de-obra. 


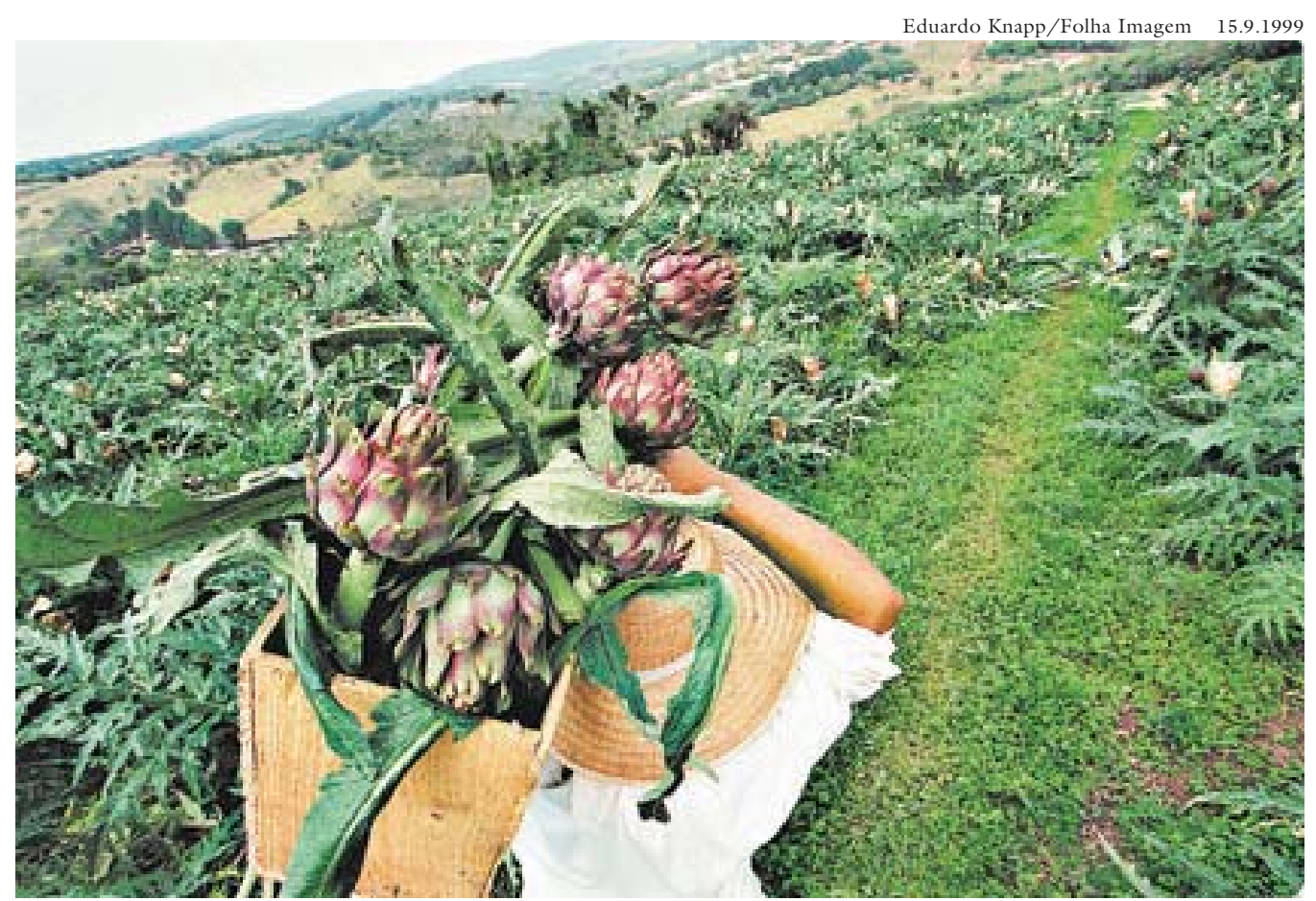

Teresinha Costa Leite carrega caixa de alcachofra colbida em Ibiúna, no interior de São Paulo.

Algumas das conseqüências mais negativas das mudanças estruturais no setor agrícola, das quais resultou uma maior heterogeneidade de situações, a maior diferenciação das condições produtivas dos pequenos e grandes produtores, e a queda do emprego, foram o aumento da pobreza e o aprofundamento da desigualdade no meio rural. Em 1980, os pobres rurais na América Latina chegavam a 73 milhões de pessoas, e em 1997 ultrapassavam os 78 milhões. Quanto aos indigentes rurais, incluídos nas cifras anteriores, haviam passado de 40 para 47 milhões $^{2}$. Quanto aos pobres urbanos, haviam aumentado de 63 milhões em 1980 para 126 milhões em 1997, enquanto os indigentes urbanos passaram de 22,5 para 42,7 milhões.

Vimos anteriormente ${ }^{3}$ que, em uma economia de mercado, a fome e a subalimentação não podem ser superadas se o conjunto dos consumidores não dispuser de renda suficiente para garantir a satisfação de suas necessidades alimentares. No caso do rendimento agrícola, isso implica um sistema de produção que não concentre a produção e a renda entre a minoria de grandes agricultores que dispõe de mais terras, de financiamento, e que pode chegar aos mercados mais favoráveis.

Mas isso é justamente o que está ocorrendo hoje em dia na América Latina, enquanto os pequenos agricultores familiares e subfamiliares ficam marginalizados, assim como os trabalhadores sem-terra. E todos eles constituem a maioria da população rural e, portanto, dos consumidores que precisam comer. Enquanto essas condições persistirem e se acentuarem, mais a segurança alimentar da população das zonas rurais será afetada. 
Por sua parte, no caso do rendimento urbano, enquanto não existirem políticas que assegurem o pleno emprego e um rendimento satisfatório aos trabalhadores urbanos, o problema da fome e da subalimentação manter-se-á e agravar-se-á. É justamente isso o que está ocorrendo hoje em dia como resultado das políticas em curso.

Se quisermos, pois, com realismo, melhorar a segurança alimentar urbana, são outras políticas muito diferentes das atuais que devem ser postas em prática.

Digamos, para finalizar, algo sobre a soberania alimentar da América Latina.

No âmbito das relações entre agricultores e grandes empresas ligadas ao setor (produtores de agroquímicos e de sementes, de agroindústrias alimentares ou de cadeia de supermercados), também se observa no período que se seguiu às reformas e no contexto da globalização, um aumento do poder de pressão dessas empresas - a maioria multinacionais - sobre os produtores agrícolas. Por trás dessa pressão crescente observa-se um processo intenso de fusões e aquisições entre os grandes grupos transnacionais (produtores de sementes, agroquímicos e alimentos, empresas biotecnológicas, grandes cadeias internacionais de supermercados etc.). Tais processos estão proporcionando uma modificação na estrutura do mercado dessas indústrias, com uma forte tendência para a concentração e a internacionalização da produção, inclusive das decisões produtivas concernentes à agricultura dos países latino-americanos ${ }^{4}$. Tudo isso ligado ao enfraquecimento do papel dos estados nacionais na formulação e aplicação das políticas setoriais para a agricultura, é o que está conduzindo ao desaparecimento da soberania alimentar dos diversos países, junto com uma intensificação das diferenças entre as regiões mais desenvolvidas e as mais pobres.

Notas

1 Ver "Desarrollo Rural en América Latina y El Caribe”, Cepal, 2001.

2 "La Brecha de la Equidad", Cepal, maio 2000, uma segunda avaliação.

3 Item "Como se apresenta hoje em dia o problema da segurança alimentar".

4 “Desarrollo Rural en América Latina y El Caribe”, Cepal, 2001, p. 83.

Referências bibliográficas

CEPAL, Desarrollo Rural en América Latina y El Caribe, 2001.

CEPAL, La Brecha de la Equidad, maio 2000.

RESUMO - ESTE artigo enfoca os problemas da situação alimentar da humanidade desde a conjuntura dos anos de 1930 até o presente. O autor, historiando o problema da relação entre a agricultura e os fenômenos da subalimentação e da fome, apresenta as possíveis opções para um futuro imediato (2010), polêmica na qual toma partido por uma das 
hipóteses em voga, não sem antes refletir sobre a situação em diversas latitudes do mundo (África, Oriente Médio...) e especificamente em Nossa América, região para a qual adverte que, dadas as mudanças na estrutura do mercado, se está produzindo uma forte tendência à concentração e internacionalização da produção, com o conseqüente desaparecimento da soberania alimentar.

PALAVRAS-CHAVE: Agricultura, Alimentação, América Latina.

ABSTRACT - THIS ARTICLE focuses on humanity's food predicaments from the 1930s to the present time. The author studies the history of the relationship between agriculture and the phenomena of undernourishment and hunger, and offers feasible options for the immediate future (2010). In this controversy, he sides with one of the ongoing hypothesis, after reflecting on the situation of several latitudes in the world (Africa, Middle East...) and, specifically, our America, a region in which he warns, given the structural changes in the marketplace, there is now a strong trend toward the concentration and internationalization of production, resulting in the disappearance of its alimentary sovereignty.

KEY-WORDS: Agriculture, Feed, Latin American.

Jacques Choncholé doutor pela Universidade de Paris I. Foi ministro da Reforma Agrária do Chile no governo de Allende. Ex-diretor do Instituto de Altos Estudos da América Latina, Universidade de Paris III, Sorbonne Nouvelle. Atual diretor do doutorado em Estudo das Sociedades Latino-americanas. Autor de várias publicações, entre as quais, Los sistemas agrários de América Latina e Hacia dónde nos lleva la globalización. @ - ocoa@vtri.net

Tradução de Gênese Andrade. O original em espanhol - "La soberania alimentaria" encontra-se à disposição do leitor no IEA-USP para eventual consulta.

Publicado originalmente em Cultura, Sociedad e Historia Contemporánea, Revista del Doctorado en el Estudio de las Sociedades Latinoamericanas, Santiago do Chile, Universidad Arcis, Editorial Arcis, 2002, pp. 269-290.

Recebido em 10.8.05 e aceito em 17.10.05. 